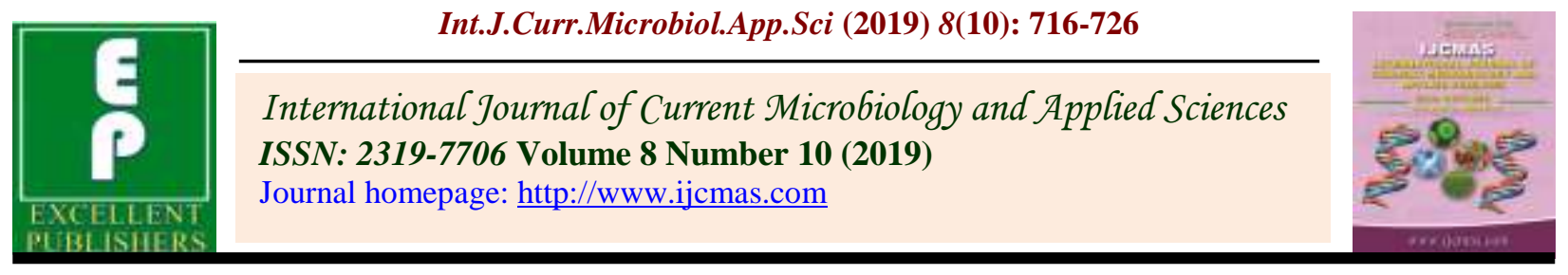

Original Research Article

https://doi.org/10.20546/ijcmas.2019.810.083

\title{
LEA Genes Play Important Role in Seed and Pod Development in Cajanus cajan
}

\author{
Antara Das ${ }^{1}$, Kuldeep Kumar ${ }^{1}$, Kishor Tribhuvan ${ }^{1}$, Rekha Joshi ${ }^{2}$, \\ Kumar Durgesh ${ }^{2}$ and Kishor Gaikwad ${ }^{1 *}$
}

${ }^{1}$ ICAR-National Institute for Plant Biotechnology, New Delhi, 110012, India

${ }^{2}$ Division of genetics and plant breeding, Indian Agricultural Research Institute, New Delhi, 110012, India

*Corresponding author

\begin{tabular}{|l|}
\hline Ke y w o r d s \\
LEA gene, Cajanus \\
cajan, Paralogs, \\
Seed and pod
\end{tabular}

A B S T R A C T
Seed and pod development is one of the important stages affecting the yield potential of a plant. Number of seeds per pod and pod length are some important yield attribute. Cajanus cajan has immense diversity in term of these traits. LEA (late embryogenesis abundant) gene family members are known to accumulate in seed and pod during several stresses and seed development. In this study we have tried to find out total number of LEA genes present in Cajanus cajan, and their phylogenetic analysis to search for the structural homologs. In this study also tried to build the heat map showing the expression level of these genes. It was found that some of the $L E A$ gene family members viz C.cajan_17192, C.cajan_21717, C.cajan_37355, C.cajan_43531, C.cajan_ 10424, C.cajan_10963, C.cajan_03928, C.cajan_20859, C.cajan_31323, C.cajan_06188, C.cajan_14597, C.cajan_35463, C.cajan_09914, C.cajan_ 09556, C.cajan_29204, C.cajan_04295, C.cajan_45355, C.cajan_00461 and C.cajan_21796 were showing up regulation in reproductive mature seeds and pods. These $L E A$ gene members may play important role in seed and pod development in pigeonpea.

\section{Introduction}

Pigeonpea (Cajanus cajan (L.) Millsp.), also known as red gram is a nutritionally rich and an important grain legume belonging to the Cajaninae sub-tribe of the tribe Phaseoleae under sub-family Papilionoideae of family
Leguminosae. It is known to be originated from India (Van der Maesen, 1980). It is one of the high protein food legumes of rainfed tropic and sub-tropic environments. Pigeonpea is a hardy crop which shows tolerance toward heat and drought though it is having susceptibility toward extended cold and water 
logging. It has diploid genome with 11 pairs of chromosomes $(2 n=2 x=22)$ and the estimated genome size is 833.07 Mbp (Varshney et al., 2012).

Many factors are accountable for stumpy productivity; like lack of superior cultivars, susceptibility toward the various pest and diseases. Proper agronomic practices have been equally important in this regard. Besides this there are many morphological characteristics which significantly hamper the yield.

Number of pods per plant, pod length and number of seeds per pod are some of them. Thus, optimization of all these factors will help us in attaining higher yield.

Seed development is one of the largely multifaceted genetically regulated as well as metabolically active process in the plant life cycle. Ultimately seeds are the final outcome of plants life cycle.

Many studies have been performed to understand the metabolic and hormonal involvement and changes during the seed development stages in legume which concerning about synthesis of carbohydrates, protein, lipids and other metabolites and their proper processing and partitioning as the form of assimilates. In case of pigeon pea it is observed that the seed development processes may require 25 to 35 days from the day of anthesis to maturation, this time period varies based on the genotype and the moisture content in the mature seeds. During seed development the proteins and soluble sugars play significant roles to getting hold of desiccation tolerance in the seeds.

During last stage of embryogenesis a group of hydrophilic proteins known as Late Embryogenesis Abundant (LEA) proteins accumulates. These proteins are also found in vegetative tissues during heat and drought condition. Due to its extensively wide range distribution from algae (Honjoh et al., 1995) to angiosperms in the plant kingdom shows its significant role in the plants during different response.

These proteins are not only coupled to water deficit caused by environmental changes but also to water constraint created during plant development under optimal growth conditions, such as during development of seeds and pollen grains, or some stages of shoot and root development (Colmenero-Flores et al., 1999; Vicient et al., 2000; Sheoran et al., 2006).

Biotic stresses such as drought, salinity, osmotic, cold, and freezing temperatures construct cellular water deficient condition, which escort to the gathering of a collection of exceedingly hydrophilic LEA proteins (Battaglia et al., 2008; Bies-Etheve et al., 2008); Hundertmark and Hincha, 2008). Some of the LEA proteins are also involved seed germination to advancement into seedling growth.

The majority of the LEA proteins recognized till now belong to hydrophilins. It is well and extensively distributed protein group containing high level of charged amino acid residues viz., glycine, alanine, serine, or threonine and lack of tryptophanes and cysteines (Garay-Arroyo et al., 2000).

In pulses investigation of LEA protein was done based on conserved amino acid sequences and seven groups named as LEA1 to LEA7 were identified. Though LEA protein was studied in pluses including Cajanus cajan, Phaseolus vulgaris, Vigna sp. but individually extensive study in Cajanus cajan LEA genes was lacking. In this study we tried to identify and characterized all LEA genes present in $C$. cajan and also to analyse their expression pattern. 


\section{Materials and Methods}

\section{Genome wide identification of LEA genes in C. cajan}

The protein sequence of LEA genes were downloaded from LIS (Legume information data base) database. We searched the LIS database using 'LEA' as key words and mRNAs as well as polypeptide sequences were downloaded in fasta format.

\section{Phylogenetic analysis to search homologs of LEA gene}

Multiple sequence alignment was performed to the protein sequences of all LEA gene via MEGA10 software to build the phylogenetic tree for all LEA protein in Cajanus cajan.

\section{Expression pattern analysis of LEA family genes using gene expression atlas}

Expression atlas of $C$. cajan developed by Pazhamala et al., (2017) from 10 tissues of a C. cajan cv. Asha and was used to visualize the expression profile of all LEA genes in different tissues. The gene expression data in the form of FPKM values of each selected genes was filtered from the gene expression atlas and used for the preparation of heatmap using ' $\mathrm{R}$ ' script.

\section{Result and Discussion}

A set of 82 LEA proteins were identified through the search option from LIS database in $C$. cajan. The information such as chromosome name, start and end position, domains present, their function are provided in table 1. Chromosome CcLG02 and CcLG03 contains most number of LEA gene i.e. both of these contains 8 LEA gene members. In terms of numbers LEA14 is the most abundant LEA protein in C. cajan, as it have 60 members. Whole phylogeny was classified into 4 major clades. Clade I contains 2 members, clade II contains 21 members, clade III contains 3 members while clade IV contains 56 members.

Both clade I members are not assigned to any further subgroup. Clade II contains all LEA3, LEA5 and some LEA 14 members. Two members of clade III i.e. cajca.C.cajan_02499.1 and cajca.C.cajan_ 21796.1 are not well characterized but they falls very close to cajca.C.cajan_10424.1, a LEA18 protein. This concludes that both of these proteins viz., cajca.C.cajan_02499.1 and cajca.C.cajan_21796.1 may be having LEA18 like function. Clade IV comprises solely of LEA14 members.

The heat map developed from expression atlas data developed by Pazhmahla et al., (2012) revealed the expression pattern of all these LEA genes. FPKM values of these particular genes in reproductive mature pod, reproductive mature seed, reproductive stamen, reproductive pistil, reproductive petal, reproductive sepal, reproductive immature pod, reproductive immature seed, reproductive bud, reproductive shoot apical meristem, reproductive petiole and reproductive leaf were used. A total of 19 LEA gene family member i.e. C.cajan_17192, C.cajan_21717, C.cajan_37355, C.cajan_43531, C.cajan_ 10424, C.cajan_10963, C.cajan_03928, C.cajan_20859, C.cajan_31323, C.cajan_ 06188, C.cajan_14597, C.cajan_35463, C.cajan_09914, C.cajan_09556, C.cajan_ 29204, C.cajan_04295, C.cajan_45355, C.cajan_00461 and C.cajan_21796 were found to be upregulated in reproductive mature bud and reproductive mature seed as compared to the reproductive immature bud and reproductive immature seed.

These LEA genes may be of primary important for transformation of reproductive immature bud and reproductive immature seed to reproductive mature bud and reproductive mature seed (Fig. 1 and 2). 
Table.1

\begin{tabular}{|c|c|c|c|c|c|c|}
\hline Name & $\begin{array}{l}\text { Chr. } \\
\text { no. }\end{array}$ & Start & End & Domain & $\begin{array}{l}\text { LEA- } \\
\text { Family }\end{array}$ & Description \\
\hline $\begin{array}{l}\text { C.cajan } \\
\text { 00461 }\end{array}$ & CcLG11 & 4337141 & 4337546 & IPR005513 & $\begin{array}{l}\text { LEA-25/ } \\
\text { LEA- } \\
\text { D113 }\end{array}$ & $\begin{array}{l}\text { seed maturation protein; IPR005513 (Late } \\
\text { embryogenesis abundant protein, LEA-25/LEA- } \\
\text { D113); GO:0009790 (embryo development) }\end{array}$ \\
\hline $\begin{array}{l}\text { C.cajan_- } \\
00500\end{array}$ & CcLG11 & 4735764 & 4736484 & IPR004864 & LEA-14 & $\begin{array}{c}\text { Late embryogenesis abundant (LEA) } \\
\text { hydroxyproline-rich glycoprotein family; } \\
\text { IPR004864 (Late embryogenesis abundant } \\
\text { protein, LEA-14) }\end{array}$ \\
\hline $\begin{array}{l}\text { C.cajan } \\
\mathbf{0 2 4 9 9}\end{array}$ & CcLG11 & 27354459 & 27356340 & IPR025423 & & $\begin{array}{l}\text { Late embryogenesis abundant protein (LEA) } \\
\text { family protein; IPR025423 (Domain of unknown } \\
\text { function DUF4149) }\end{array}$ \\
\hline C.cajan_- $_{\mathbf{0 3 9 2 8}}$ & CcLG11 & 43136957 & 43138475 & IPR004238 & LEA-3 & $\begin{array}{l}\text { late embryogenesis abundant protein, putative / } \\
\text { LEA protein, putative; IPR004238 (Late } \\
\text { embryogenesis abundant protein, LEA-3) }\end{array}$ \\
\hline C.cajan $_{\mathbf{0 4 2 9 5}}$ & CcLG11 & 46876402 & 46876624 & IPR004926 & LEA-5 & $\begin{array}{l}\text { Late embryogenesis abundant } 3 \text { (LEA3) family } \\
\text { protein; IPR004926 (Late embryogenesis } \\
\text { abundant protein, LEA-5); GO:0006950 (response } \\
\text { to stress) }\end{array}$ \\
\hline $\begin{array}{l}\text { C.cajan } \\
\mathbf{0 5 6 5 8}\end{array}$ & CcLG02 & 12473333 & 12474143 & IPR004864 & LEA-14 & $\begin{array}{c}\text { Late embryogenesis abundant (LEA) } \\
\text { hydroxyproline-rich glycoprotein family; } \\
\text { IPR004864 (Late embryogenesis abundant } \\
\text { protein, LEA-14) }\end{array}$ \\
\hline $\begin{array}{c}\text { C.cajan_- } \\
05699\end{array}$ & CcLG02 & 12813034 & 12814144 & $\begin{array}{l}\text { IPR004864, } \\
\text { IPR004864 }\end{array}$ & LEA-14 & $\begin{array}{l}\text { late embryogenesis abundant protein; IPR004864 } \\
\text { (Late embryogenesis abundant protein, LEA-14), } \\
\text { IPR004864 (Immunoglobulin-like fold); } \\
\text { GO:0009269 (response to desiccation) }\end{array}$ \\
\hline $\begin{array}{l}\text { C.cajan } \\
\text { 05978 }\end{array}$ & CcLG02 & 15418451 & 15419144 & IPR004864 & LEA-14 & $\begin{array}{c}\text { Late embryogenesis abundant (LEA) } \\
\text { hydroxyproline-rich glycoprotein family; } \\
\text { IPR004864 (Late embryogenesis abundant } \\
\text { protein, LEA-14) }\end{array}$ \\
\hline $\begin{array}{l}\text { C.cajan_- } \\
\text { 06049 }\end{array}$ & CcLG02 & 16405988 & 16406904 & NA & & $\begin{array}{l}\text { Late embryogenesis abundant protein (LEA) } \\
\text { family protein }\end{array}$ \\
\hline${ }_{\text {C6188 }}^{\text {C.cajan }}$ & CcLG02 & 17870000 & 17871698 & IPR004238 & LEA-3 & $\begin{array}{l}\text { late embryogenesis abundant protein, putative / } \\
\text { LEA protein, putative; IPR004238 (Late } \\
\text { embryogenesis abundant protein, LEA-3) }\end{array}$ \\
\hline $\begin{array}{l}\text { C.cajan__- } \\
06305^{-}\end{array}$ & CcLG02 & 19270566 & 19271535 & IPR004864 & LEA-14 & $\begin{array}{l}\text { protein YLS9 [Glycine max]; IPR004864 (Late } \\
\text { embryogenesis abundant protein, LEA-14) }\end{array}$ \\
\hline${ }_{06725}^{\text {C.cajan }}$ & CcLG02 & 24130143 & 24130788 & IPR004926 & LEA-5 & $\begin{array}{l}\text { Late embryogenesis abundant } 3 \text { (LEA3) family } \\
\text { protein; IPR004926 (Late embryogenesis } \\
\text { abundant protein, LEA-5); GO:0006950 (response } \\
\text { to stress) }\end{array}$ \\
\hline $\begin{array}{l}\text { C.cajan__- } \\
\mathbf{0 7 9 9 3}\end{array}$ & CcLG02 & 36538747 & 36539626 & IPR004864 & LEA-14 & $\begin{array}{l}\text { Late embryogenesis abundant (LEA) } \\
\text { hydroxyproline-rich glycoprotein family; } \\
\text { IPR004864 (Late embryogenesis abundant } \\
\text { protein, LEA-14) }\end{array}$ \\
\hline C.cajan_ & CcLG03 & 12841276 & 12842044 & IPR004864 & LEA-14 & Late embryogenesis abundant (LEA) \\
\hline
\end{tabular}




\begin{tabular}{|c|c|c|c|c|c|c|}
\hline 09281 & & & & & & $\begin{array}{l}\text { hydroxyproline-rich glycoprotein family; } \\
\text { IPR004864 (Late embryogenesis abundant } \\
\text { protein, LEA-14) }\end{array}$ \\
\hline $\begin{array}{l}\text { C.cajan__- } \\
09556\end{array}$ & CcLG03 & 15642569 & 15643139 & IPR005513 & $\begin{array}{l}\text { LEA-25/ } \\
\text { LEA- } \\
\text { D113 }\end{array}$ & $\begin{array}{l}\text { seed maturation protein; IPR005513 (Late } \\
\text { embryogenesis abundant protein, LEA-25/LEA- } \\
\text { D113); GO:0009790 (embryo development) }\end{array}$ \\
\hline $\begin{array}{l}\text { C.cajan } \\
09914\end{array}$ & CcLG03 & 19363346 & 19363997 & IPR004238 & LEA-3 & $\begin{array}{c}35 \mathrm{kDa} \text { seed maturation protein [Glycine max]; } \\
\text { IPR004238 (Late embryogenesis abundant } \\
\text { protein, LEA-3) }\end{array}$ \\
\hline $\begin{array}{l}\text { C.cajan } \\
10424\end{array}$ & CcLG03 & 23987705 & 23987948 & IPR018930 & LEA-18 & $\begin{array}{c}\text { Late embryogenesis abundant protein, group 6; } \\
\text { IPR018930 (Late embryogenesis abundant } \\
\text { protein, LEA-18) }\end{array}$ \\
\hline $\begin{array}{c}\text { C.cajan } \\
10532\end{array}$ & CcLG03 & 25145030 & 25145813 & IPR004864 & LEA-14 & $\begin{array}{l}\text { protein YLS9 [Glycine max]; IPR004864 (Late } \\
\text { embryogenesis abundant protein, LEA-14) }\end{array}$ \\
\hline $\begin{array}{c}\text { C.cajan } \\
10818\end{array}$ & CcLG03 & 27827288 & 27827672 & IPR004926 & LEA-5 & $\begin{array}{c}\text { late embryogenesis abundant protein; IPR004926 } \\
\text { (Late embryogenesis abundant protein, LEA-5); } \\
\text { GO:0006950 (response to stress) }\end{array}$ \\
\hline $\begin{array}{l}\text { C.cajan } \\
10963\end{array}$ & CcLG03 & 28997247 & 28997841 & IPR004864 & LEA-14 & $\begin{array}{c}\text { Late embryogenesis abundant (LEA) } \\
\text { hydroxyproline-rich glycoprotein family; } \\
\text { IPR004864 (Late embryogenesis abundant } \\
\text { protein, LEA-14) }\end{array}$ \\
\hline $\begin{array}{c}\text { C.cajan } \\
10997\end{array}$ & CcLG03 & 29303412 & 29303877 & IPR004864 & LEA-14 & $\begin{array}{l}\text { Late embryogenesis abundant hydroxyproline- } \\
\text { rich glycoprotein family, putative n=1 } \\
\text { Tax=Theobroma cacao RepID=UPI00042B1EF8; } \\
\text { IPR004864 (Late embryogenesis abundant } \\
\text { protein, LEA-14) }\end{array}$ \\
\hline $\mathrm{C.cajan}_{11442}$ & CcLG06 & 4615050 & 4616742 & IPR004864 & LEA-14 & $\begin{array}{l}\text { uncharacterized protein LOC100811519 [Glycine } \\
\text { max]; IPR004864 (Late embryogenesis abundant } \\
\text { protein, LEA-14) }\end{array}$ \\
\hline $\begin{array}{l}\text { C.cajan } \\
12887\end{array}$ & CcLG06 & 19537893 & 19539944 & IPR004864 & LEA-14 & $\begin{array}{l}\text { late embryogenesis abundant protein; IPR004864 } \\
\text { (Late embryogenesis abundant protein, LEA-14) }\end{array}$ \\
\hline $\begin{array}{c}\text { C.cajan } \\
13277\end{array}$ & CcLG06 & 23254692 & 23255256 & IPR004864 & LEA-14 & $\begin{array}{c}\text { Late embryogenesis abundant (LEA) } \\
\text { hydroxyproline-rich glycoprotein family; } \\
\text { IPR004864 (Late embryogenesis abundant } \\
\text { protein, LEA-14) }\end{array}$ \\
\hline $\begin{array}{c}\text { C.cajan } \\
13655\end{array}$ & CcLG10 & 3270951 & 3271617 & $\begin{array}{l}\text { IPR004864, } \\
\text { IPR013783 }\end{array}$ & LEA-14 & $\begin{array}{l}\text { Late embryogenesis abundant (LEA) } \\
\text { hydroxyproline-rich glycoprotein family; } \\
\text { IPR004864 (Late embryogenesis abundant } \\
\text { protein, LEA-14), IPR013783 (Immunoglobulin- } \\
\text { like fold) }\end{array}$ \\
\hline $\begin{array}{l}\text { C.cajan } \\
13744\end{array}$ & CcLG10 & 4153772 & 4154141 & IPR004864 & LEA-14 & $\begin{array}{c}\text { Late embryogenesis abundant (LEA) } \\
\text { hydroxyproline-rich glycoprotein family; } \\
\text { IPR004864 (Late embryogenesis abundant } \\
\text { protein, LEA-14) }\end{array}$ \\
\hline $\begin{array}{c}\text { C.cajan } \\
13745\end{array}$ & CcLG10 & 4165613 & 4166177 & IPR004864 & LEA-14 & $\begin{array}{c}\text { Late embryogenesis abundant (LEA) } \\
\text { hydroxyproline-rich glycoprotein family; } \\
\text { IPR004864 (Late embryogenesis abundant } \\
\text { protein, LEA-14) }\end{array}$ \\
\hline C.cajan_ & CcLG10 & 14360576 & 14361272 & NA & & Late embryogenesis abundant protein (LEA) \\
\hline
\end{tabular}




\begin{tabular}{|c|c|c|c|c|c|c|}
\hline 14597 & & & & & & family protein \\
\hline $\begin{array}{c}\text { C.cajan } \\
14840\end{array}$ & CcLG10 & 16958021 & 16958600 & $\begin{array}{l}\text { IPR004864, } \\
\text { IPR013783 }\end{array}$ & LEA-14 & $\begin{array}{l}\text { Late embryogenesis abundant (LEA) } \\
\text { hydroxyproline-rich glycoprotein family; } \\
\text { IPR004864 (Late embryogenesis abundant } \\
\text { protein, LEA-14), IPR013783 (Immunoglobulin- } \\
\text { like fold) }\end{array}$ \\
\hline $\begin{array}{c}\text { C.cajan } \\
15135\end{array}$ & CcLG10 & 20124814 & 20125555 & IPR004864 & LEA-14 & $\begin{array}{l}\text { protein YLS9 [Glycine max]; IPR004864 (Late } \\
\text { embryogenesis abundant protein, LEA-14) }\end{array}$ \\
\hline $\begin{array}{c}\text { C.cajan } \\
15504\end{array}$ & CcLG08 & 1770036 & 1770594 & IPR004864 & LEA-14 & $\begin{array}{l}\text { protein YLS9-like [Glycine max]; IPR004864 } \\
\text { (Late embryogenesis abundant protein, LEA-14) }\end{array}$ \\
\hline $\begin{array}{c}\text { C.cajan } \\
15522\end{array}$ & CcLG08 & 1887897 & 1888992 & IPR004864 & LEA-14 & $\begin{array}{l}\text { uncharacterized protein LOC100787767 [Glycine } \\
\text { max]; IPR004864 (Late embryogenesis abundant } \\
\text { protein, LEA-14) }\end{array}$ \\
\hline $\begin{array}{l}\text { C.cajan } \\
16206\end{array}$ & CcLG08 & 9717806 & 9718436 & IPR004864 & LEA-14 & $\begin{array}{c}\text { Late embryogenesis abundant (LEA) } \\
\text { hydroxyproline-rich glycoprotein family; } \\
\text { IPR004864 (Late embryogenesis abundant } \\
\text { protein, LEA-14) }\end{array}$ \\
\hline $\begin{array}{l}\text { C.cajan } \\
17192\end{array}$ & CcLG08 & 19359194 & 19361713 & IPR004864 & LEA-14 & $\begin{array}{c}\text { Late embryogenesis abundant (LEA) } \\
\text { hydroxyproline-rich glycoprotein family; } \\
\text { IPR004864 (Late embryogenesis abundant } \\
\text { protein, LEA-14) }\end{array}$ \\
\hline $\begin{array}{l}\text { C.cajan } \\
20707\end{array}$ & CcLG01 & 16077098 & 16077791 & IPR004864 & LEA-14 & $\begin{array}{l}\text { Late embryogenesis abundant (LEA) } \\
\text { hydroxyproline-rich glycoprotein family; } \\
\text { IPR004864 (Late embryogenesis abundant } \\
\text { protein, LEA-14) }\end{array}$ \\
\hline $\begin{array}{l}\text { C.cajan } \\
20854\end{array}$ & CcLG01 & 17614454 & 17615117 & IPR004864 & LEA-14 & $\begin{array}{c}\text { Late embryogenesis abundant (LEA) } \\
\text { hydroxyproline-rich glycoprotein family; } \\
\text { IPR004864 (Late embryogenesis abundant } \\
\text { protein, LEA-14) }\end{array}$ \\
\hline $\begin{array}{l}\text { C.cajan } \\
20859\end{array}$ & CcLG01 & 17636185 & 17636797 & $\begin{array}{l}\text { IPR004864, } \\
\text { IPR013783 }\end{array}$ & LEA-14 & $\begin{array}{l}\text { Late embryogenesis abundant protein; IPR004864 } \\
\text { (Late embryogenesis abundant protein, LEA-14), } \\
\text { IPR013783 (Immunoglobulin-like fold); } \\
\text { GO:0009269 (response to desiccation) }\end{array}$ \\
\hline $\begin{array}{l}\text { C.cajan } \\
21068\end{array}$ & CcLG04 & 1997430 & 1999176 & IPR004864 & LEA-14 & $\begin{array}{l}\text { late embryogenesis abundant protein; IPR004864 } \\
\text { (Late embryogenesis abundant protein, LEA-14) }\end{array}$ \\
\hline $\begin{array}{l}\text { C.cajan } \\
21674\end{array}$ & CcLG04 & 7986489 & 7987122 & NA & & late embryogenesis abundant protein \\
\hline $\begin{array}{c}\text { C.cajan } \\
21676\end{array}$ & CcLG04 & 8014879 & 8015677 & IPR004864 & LEA-14 & $\begin{array}{l}\text { Late embryogenesis abundant (LEA) } \\
\text { hydroxyproline-rich glycoprotein family; } \\
\text { IPR004864 (Late embryogenesis abundant } \\
\text { protein, LEA-14) }\end{array}$ \\
\hline $\begin{array}{l}\text { C.cajan } \\
21717\end{array}$ & CcLG04 & 8355887 & 8356442 & IPR004864 & LEA-14 & $\begin{array}{c}\text { Late embryogenesis abundant (LEA) } \\
\text { hydroxyproline-rich glycoprotein family; } \\
\text { IPR004864 (Late embryogenesis abundant } \\
\text { protein, LEA-14); GO:0009269 (response to } \\
\text { desiccation) }\end{array}$ \\
\hline $\begin{array}{l}\text { C.cajan_- } \\
21796\end{array}$ & CcLG04 & 8989147 & 8990184 & IPR025423 & & $\begin{array}{l}\text { Late embryogenesis abundant protein (LEA) } \\
\text { family protein; IPR025423 (Domain of unknown } \\
\text { function DUF4149) }\end{array}$ \\
\hline
\end{tabular}




\begin{tabular}{|c|c|c|c|c|c|c|}
\hline $\begin{array}{l}\text { C.cajan } \\
22736\end{array}$ & CcLG09 & 6775857 & 6776442 & IPR004864 & LEA-14 & $\begin{array}{l}\text { uncharacterized protein LOC100797168 [Glycine } \\
\text { max]; IPR004864 (Late embryogenesis abundant } \\
\text { protein, LEA-14) }\end{array}$ \\
\hline $\begin{array}{l}\text { C.cajan } \\
22769\end{array}$ & CcLG09 & 7226278 & 7227061 & IPR004864 & LEA-14 & $\begin{array}{c}\text { Late embryogenesis abundant (LEA) } \\
\text { hydroxyproline-rich glycoprotein family; } \\
\text { IPR004864 (Late embryogenesis abundant } \\
\text { protein, LEA-14) }\end{array}$ \\
\hline $\begin{array}{l}\text { C.cajan } \\
23280\end{array}$ & CcLG05 & 2045435 & 2045903 & IPR004864 & LEA-14 & $\begin{array}{l}\text { protein YLS9-like [Glycine max]; IPR004864 } \\
\text { (Late embryogenesis abundant protein, LEA-14) }\end{array}$ \\
\hline $\begin{array}{l}\text { C.cajan } \\
24412\end{array}$ & $\begin{array}{l}\text { Scaffold } \\
000046\end{array}$ & 908804 & 909962 & IPR005513 & $\begin{array}{l}\text { LEA-25/ } \\
\text { LEA- } \\
\text { D113 }\end{array}$ & $\begin{array}{c}\text { late embryogenesis abundant protein; IPR005513 } \\
\text { (Late embryogenesis abundant protein, LEA- } \\
\text { 25/LEA-D113); GO:0009790 (embryo } \\
\text { development) }\end{array}$ \\
\hline $\begin{array}{l}\text { C.cajan } \\
25044\end{array}$ & $\begin{array}{l}\text { Scaffold } \\
127746\end{array}$ & 500414 & 500783 & IPR004926 & LEA-5 & $\begin{array}{c}\text { late embryogenesis abundant protein; IPR004926 } \\
\text { (Late embryogenesis abundant protein, LEA-5); } \\
\text { GO:0006950 (response to stress) }\end{array}$ \\
\hline $\begin{array}{l}\text { C.cajan } \\
25170\end{array}$ & $\begin{array}{c}\text { Scaffold } \\
000321\end{array}$ & 151017 & 151650 & IPR004864 & LEA-14 & $\begin{array}{l}\text { protein YLS9-like [Glycine max]; IPR004864 } \\
\text { (Late embryogenesis abundant protein, LEA-14) }\end{array}$ \\
\hline $\begin{array}{l}\text { C.cajan }_{-} \\
25699\end{array}$ & $\begin{array}{l}\text { Scaffold } \\
000332\end{array}$ & 214072 & 214786 & IPR004864 & LEA-14 & $\begin{array}{c}\text { Late embryogenesis abundant (LEA) } \\
\text { hydroxyproline-rich glycoprotein family; } \\
\text { IPR004864 (Late embryogenesis abundant } \\
\text { protein, LEA-14) }\end{array}$ \\
\hline $\begin{array}{l}\text { C.cajan } \\
26931\end{array}$ & $\begin{array}{l}\text { Scaffold } \\
128870\end{array}$ & 108738 & 109659 & IPR004864 & LEA-14 & $\begin{array}{c}\text { Late embryogenesis abundant (LEA) } \\
\text { hydroxyproline-rich glycoprotein family; } \\
\text { IPR004864 (Late embryogenesis abundant } \\
\text { protein, LEA-14) }\end{array}$ \\
\hline $\begin{array}{c}\text { C.cajan } \\
26932\end{array}$ & $\begin{array}{l}\text { Scaffold } \\
128870\end{array}$ & 124905 & 125535 & IPR004864 & LEA-14 & $\begin{array}{l}\text { protein YLS9-like [Glycine max]; IPR004864 } \\
\text { (Late embryogenesis abundant protein, LEA-14) }\end{array}$ \\
\hline $\begin{array}{l}\text { C.cajan } \\
26934\end{array}$ & $\begin{array}{l}\text { Scaffold } \\
128870\end{array}$ & 162312 & 162978 & IPR004864 & LEA-14 & $\begin{array}{l}\text { protein YLS9 [Glycine max]; IPR004864 (Late } \\
\text { embryogenesis abundant protein, LEA-14) }\end{array}$ \\
\hline $\begin{array}{l}\text { C.cajan } \\
26943\end{array}$ & $\begin{array}{c}\text { Scaffold } \\
128870\end{array}$ & 216816 & 217317 & IPR004864 & LEA-14 & $\begin{array}{c}\text { Late embryogenesis abundant (LEA) } \\
\text { hydroxyproline-rich glycoprotein family; } \\
\text { IPR004864 (Late embryogenesis abundant } \\
\text { protein, LEA-14) }\end{array}$ \\
\hline $\begin{array}{l}\text { C.cajan } \\
27095\end{array}$ & $\begin{array}{l}\text { Scaffold } \\
000144\end{array}$ & 144731 & 145714 & IPR004864 & LEA-14 & $\begin{array}{c}\text { Late embryogenesis abundant (LEA) } \\
\text { hydroxyproline-rich glycoprotein family; } \\
\text { IPR004864 (Late embryogenesis abundant } \\
\text { protein, LEA-14) }\end{array}$ \\
\hline $\begin{array}{l}\text { C.cajan } \\
27530\end{array}$ & $\begin{array}{l}\text { Scaffold } \\
000159\end{array}$ & 249736 & 250420 & IPR004864 & LEA-14 & $\begin{array}{l}\text { Late embryogenesis abundant (LEA) } \\
\text { hydroxyproline-rich glycoprotein family; } \\
\text { IPR004864 (Late embryogenesis abundant } \\
\text { protein, LEA-14) }\end{array}$ \\
\hline $\begin{array}{l}\text { C.cajan } \\
27598\end{array}$ & $\begin{array}{l}\text { Scaffold } \\
132776\end{array}$ & 453667 & 456495 & IPR004864 & LEA-14 & $\begin{array}{c}\text { Late embryogenesis abundant (LEA) } \\
\text { hydroxyproline-rich glycoprotein family; } \\
\text { IPR004864 (Late embryogenesis abundant } \\
\text { protein, LEA-14) }\end{array}$ \\
\hline $\begin{array}{l}\text { C.cajan } \\
27619\end{array}$ & $\begin{array}{c}\text { Scaffold } \\
133584\end{array}$ & 141240 & 141717 & IPR004864 & LEA-14 & $\begin{array}{l}\text { Late embryogenesis abundant (LEA) } \\
\text { hydroxyproline-rich glycoprotein family; } \\
\text { IPR004864 (Late embryogenesis abundant }\end{array}$ \\
\hline
\end{tabular}




\begin{tabular}{|c|c|c|c|c|c|c|}
\hline & & & & & & protein, LEA-14) \\
\hline $\begin{array}{c}\text { C.cajan_- } \\
29121\end{array}$ & $\begin{array}{c}\text { Scaffold } \\
127472\end{array}$ & 83282 & 83848 & $\begin{array}{l}\text { IPR004864, } \\
\text { IPR013783 }\end{array}$ & LEA-14 & $\begin{array}{l}\text { Late embryogenesis abundant protein; IPR004864 } \\
\text { (Late embryogenesis abundant protein, LEA-14), } \\
\text { IPR013783 (Immunoglobulin-like fold); } \\
\text { GO:0009269 (response to desiccation) }\end{array}$ \\
\hline $\begin{array}{l}\text { C.cajan_- } \\
29142\end{array}$ & $\begin{array}{c}\text { Scaffold } \\
127472\end{array}$ & 285988 & 287854 & NA & & $\begin{array}{l}\text { Late embryogenesis abundant protein (LEA) } \\
\text { family protein }\end{array}$ \\
\hline $\begin{array}{l}\text { C.cajan } \\
29209\end{array}$ & $\begin{array}{c}\text { Scaffold } \\
127411\end{array}$ & 160686 & 161074 & IPR000389 & $\begin{array}{l}\text { LEA- } \\
\text { B19.1A }\end{array}$ & $\begin{array}{l}\text { late embryogenesis abundant protein B19.1A; } \\
\text { IPR000389 (Stress induced protein) }\end{array}$ \\
\hline $\begin{array}{c}\text { C.cajan } \\
31323\end{array}$ & $\begin{array}{c}\text { Scaffold } \\
000286\end{array}$ & 24310 & 25219 & NA & & $\begin{array}{c}\text { Late embryogenesis abundant protein (LEA) } \\
\text { family protein }\end{array}$ \\
\hline $\begin{array}{c}\text { C.cajan_- } \\
33267\end{array}$ & $\begin{array}{c}\text { Scaffold } \\
130593\end{array}$ & 192997 & 193747 & IPR004864 & LEA-14 & $\begin{array}{c}\text { Late embryogenesis abundant (LEA) } \\
\text { hydroxyproline-rich glycoprotein family; } \\
\text { IPR004864 (Late embryogenesis abundant } \\
\text { protein, LEA-14) }\end{array}$ \\
\hline $\begin{array}{c}\text { C.cajan_- } \\
34938\end{array}$ & $\begin{array}{c}\text { Scaffold } \\
133177\end{array}$ & 30950 & 31586 & IPR004864 & LEA-14 & $\begin{array}{c}\text { Late embryogenesis abundant (LEA) } \\
\text { hydroxyproline-rich glycoprotein family; } \\
\text { IPR004864 (Late embryogenesis abundant } \\
\text { protein, LEA-14) }\end{array}$ \\
\hline C.cajan & $\begin{array}{c}\text { Scaffold } \\
133177\end{array}$ & 34525 & 34951 & IPR004864 & LEA-14 & $\begin{array}{c}\text { Late embryogenesis abundant (LEA) } \\
\text { hydroxyproline-rich glycoprotein family; } \\
\text { IPR004864 (Late embryogenesis abundant } \\
\text { protein, LEA-14) }\end{array}$ \\
\hline $\begin{array}{c}\text { C.cajan_- } \\
35463\end{array}$ & $\begin{array}{c}\text { Scaffold } \\
131636\end{array}$ & 152855 & 153339 & IPR000167 & & $\begin{array}{c}\text { late embryogenesis abundant protein-like } \\
\text { [Glycine max]; IPR000167 (Dehydrin); } \\
\text { GO:0006950 (response to stress), GO:0009415 } \\
\text { (response to water) }\end{array}$ \\
\hline $\begin{array}{c}\text { C.cajan_- } \\
35879\end{array}$ & $\begin{array}{c}\text { Scaffold } \\
133195\end{array}$ & 129374 & 130544 & IPR004864 & LEA-14 & $\begin{array}{c}\text { uncharacterized protein LOC100798888 [Glycine } \\
\text { max]; IPR004864 (Late embryogenesis abundant } \\
\text { protein, LEA-14) }\end{array}$ \\
\hline $\begin{array}{c}\text { C.cajan_- } \\
36841\end{array}$ & $\begin{array}{c}\text { Scaffold } \\
135508\end{array}$ & 32862 & 33528 & IPR004864 & LEA-14 & $\begin{array}{c}\text { Late embryogenesis abundant (LEA) } \\
\text { hydroxyproline-rich glycoprotein family; } \\
\text { IPR004864 (Late embryogenesis abundant } \\
\text { protein, LEA-14) }\end{array}$ \\
\hline $\begin{array}{c}\text { C.cajan_- } \\
36842\end{array}$ & $\begin{array}{c}\text { Scaffold } \\
135508\end{array}$ & 44449 & 44989 & IPR004864 & LEA-14 & $\begin{array}{c}\text { Late embryogenesis abundant (LEA) } \\
\text { hydroxyproline-rich glycoprotein family; } \\
\text { IPR004864 (Late embryogenesis abundant } \\
\text { protein, LEA-14) }\end{array}$ \\
\hline $\begin{array}{c}\text { C.cajan_- } \\
37355\end{array}$ & $\frac{\text { Scaffold }}{133269}$ & 88667 & 89231 & IPR004864 & LEA-14 & $\begin{array}{l}\text { Late embryogenesis abundant hydroxyproline- } \\
\text { rich glycofamily protein } \mathrm{n}=1 \text { Tax=Theobroma } \\
\text { cacao RepID=UPI00042B23A2; IPR004864 (Late } \\
\text { embryogenesis abundant protein, LEA-14) }\end{array}$ \\
\hline $\begin{array}{c}\text { C.cajan_- } \\
37356\end{array}$ & $\begin{array}{c}\text { Scaffold } \\
133269\end{array}$ & 95199 & 95730 & IPR004864 & LEA-14 & $\begin{array}{c}\text { Late embryogenesis abundant (LEA) } \\
\text { hydroxyproline-rich glycoprotein family; } \\
\text { IPR004864 (Late embryogenesis abundant } \\
\text { protein, LEA-14) }\end{array}$ \\
\hline $\begin{array}{l}\text { C.cajan } \\
39866\end{array}$ & $\begin{array}{c}\text { Scaffold } \\
132067\end{array}$ & 130160 & 130562 & IPR004864 & LEA-14 & $\begin{array}{l}\text { protein YLS9-like [Glycine max]; IPR004864 } \\
\text { (Late embryogenesis abundant protein, LEA-14) }\end{array}$ \\
\hline C.cajan_ & Scaffold & 43522 & 44077 & IPR004864 & LEA-14 & Late embryogenesis abundant (LEA) \\
\hline
\end{tabular}




\begin{tabular}{|c|c|c|c|c|c|c|}
\hline 41026 & 133482 & & & & & $\begin{array}{c}\text { hydroxyproline-rich glycoprotein family; } \\
\text { IPR004864 (Late embryogenesis abundant } \\
\text { protein, LEA-14) }\end{array}$ \\
\hline $\begin{array}{l}\text { C.cajan } \\
41555\end{array}$ & $\begin{array}{c}\text { Scaffold } \\
126477\end{array}$ & 15837 & 17915 & IPR004864 & LEA-14 & $\begin{array}{l}\text { late embryogenesis abundant protein; IPR004864 } \\
\text { (Late embryogenesis abundant protein, LEA-14) }\end{array}$ \\
\hline $\begin{array}{l}\text { C.cajan } \\
41962\end{array}$ & $\begin{array}{c}\text { Scaffold } \\
133864\end{array}$ & 2357 & 3138 & IPR004926 & LEA-5 & $\begin{array}{l}\text { Late embryogenesis abundant } 3 \text { (LEA3) family } \\
\text { protein; IPR004926 (Late embryogenesis } \\
\text { abundant protein, LEA-5); GO:0006950 (response } \\
\text { to stress) }\end{array}$ \\
\hline $\begin{array}{c}\text { C.cajan_ } \\
43531\end{array}$ & $\begin{array}{c}\text { Scaffold } \\
132354\end{array}$ & 17752 & 18265 & IPR004864 & LEA-14 & $\begin{array}{c}\text { uncharacterized protein [Glycine max]; } \\
\text { IPR004864 (Late embryogenesis abundant } \\
\text { protein, LEA-14) }\end{array}$ \\
\hline $\begin{array}{c}\text { C.cajan } \\
43533\end{array}$ & $\begin{array}{c}\text { Scaffold } \\
132354\end{array}$ & 77454 & 78051 & IPR004864 & LEA-14 & $\begin{array}{l}\text { late embryogenesis abundant protein; IPR004864 } \\
\text { (Late embryogenesis abundant protein, LEA-14) }\end{array}$ \\
\hline $\begin{array}{c}\text { C.cajan_ } \\
43535\end{array}$ & $\begin{array}{c}\text { Scaffold } \\
132354\end{array}$ & 101430 & 102024 & IPR004864 & LEA-14 & $\begin{array}{c}\text { Late embryogenesis abundant (LEA) } \\
\text { hydroxyproline-rich glycoprotein family; } \\
\text { IPR004864 (Late embryogenesis abundant } \\
\text { protein, LEA-14) }\end{array}$ \\
\hline $\begin{array}{l}\text { C.cajan } \\
43908\end{array}$ & $\begin{array}{c}\text { Scaffold } \\
134929\end{array}$ & 16099 & 16759 & IPR004864 & LEA-14 & $\begin{array}{l}\text { protein YLS9-like [Glycine max]; IPR004864 } \\
\text { (Late embryogenesis abundant protein, LEA-14) }\end{array}$ \\
\hline $\begin{array}{c}\text { C.cajan_- } \\
45355\end{array}$ & $\begin{array}{c}\text { Scaffold } \\
137131\end{array}$ & 22392 & 23343 & IPR005513 & $\begin{array}{l}\text { LEA-25/ } \\
\text { LEA- } \\
\text { D113 }\end{array}$ & $\begin{array}{l}\text { seed maturation protein; IPR005513 (Late } \\
\text { embryogenesis abundant protein, LEA-25/LEA- } \\
\text { D113); GO:0009790 (embryo development) }\end{array}$ \\
\hline $\begin{array}{l}\text { C.cajan } \\
47118\end{array}$ & $\begin{array}{c}\text { Scaffold } \\
117591\end{array}$ & 23 & 707 & IPR004864 & LEA-14 & $\begin{array}{l}\text { protein YLS9-like [Glycine max]; IPR004864 } \\
\text { (Late embryogenesis abundant protein, LEA-14) }\end{array}$ \\
\hline $\begin{array}{l}\text { C.cajan } \\
47458\end{array}$ & $\begin{array}{c}\text { Scaffold } \\
132160\end{array}$ & 20344 & 21025 & IPR004864 & LEA-14 & $\begin{array}{l}\text { protein YLS9 [Glycine max]; IPR004864 (Late } \\
\text { embryogenesis abundant protein, LEA-14) }\end{array}$ \\
\hline $\begin{array}{l}\text { C.cajan } \\
48607\end{array}$ & $\begin{array}{l}\text { Scaffold } \\
135722\end{array}$ & 24542 & 25490 & $\begin{array}{l}\text { IPR004864, } \\
\text { IPR013783 }\end{array}$ & LEA-14 & $\begin{array}{l}\text { late embryogenesis abundant protein; IPR004864 } \\
\text { (Late embryogenesis abundant protein, LEA-14), } \\
\text { IPR013783 (Immunoglobulin-like fold); } \\
\text { GO:0009269 (response to desiccation) }\end{array}$ \\
\hline
\end{tabular}

Fig.1 Heat map showing expression pattern of all 82 LEA genes in different tissues

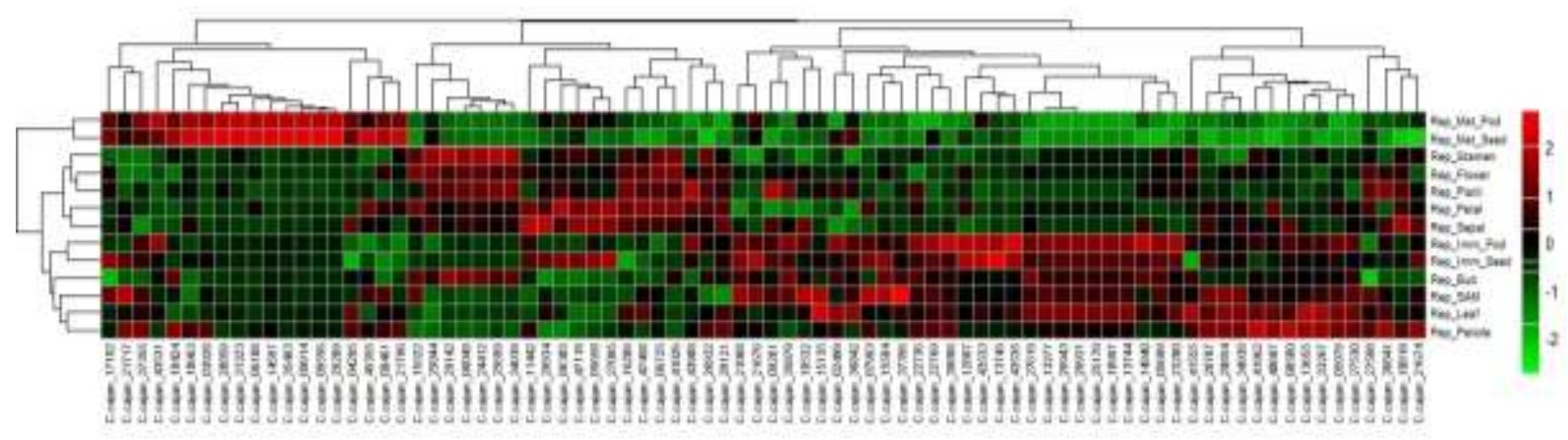


Fig.2 Phylogenetic analysis result depicted the presence of paralogs of LEA gene family members.

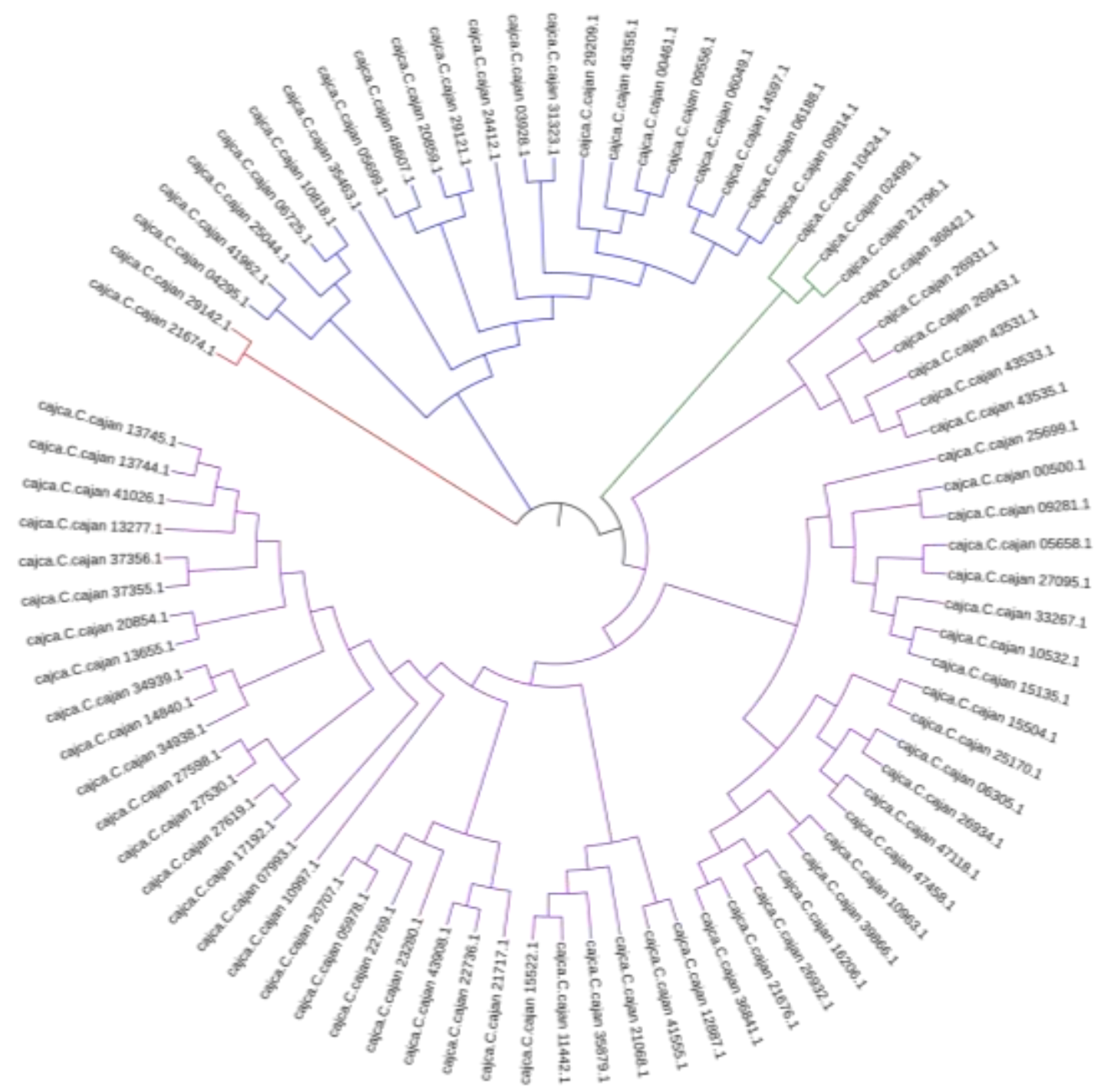

\section{Abbreviations}

LEA (late embryogenesis abundant)

\section{References}

Van der Maesen LJG (1980) India is the native home of pigeonpea. In: Arends JC, Boelema G, de Groot CT, Leeuwenberg AJM, Veenman $\mathrm{H}$, Zonen BV(Eds) Libergratulatorius in honorem H.C.D. de Witlandbouwhoge school, Miscellaneous paper no. 19, Wageningen, Netherlands, pp 257-262 Varshney, R.K. et al., Draft genome sequence of pigeonpea (Cajanus cajan), an orphan legume crop of resource-poor farmers. Nat. Biotechnol. 30, 83-89 (2012)

Honjoh, K., Yoshimoto, M., Joh, T., Kajiwara, T., Miyamoto, T., and Hatano, S. (1995). Isolation and characterization of hardening-induced proteins in Chlorella 
identification of late embryogenesis abundant proteins. Plant Cell Physiol. 36, 1421-1430

Colmenero-Flores JM, Moreno LP, Smith CE, Covarrubias AA. Pvlea-18, a member of a new late-embryogenesis-abundant protein family that accumulates during water stress and in the growing regions of well-irrigated bean seedlings. Plant Physiol. 1999;120(1):93-104. doi:10.1104/pp.120.1.93

Vicient CM, Hull G, Guilleminot J, Devic M, Delseny M (2000) Differential expression of the Arabidopsis genes coding for Em-like proteins. J Exp Bot 51 1211-1220

Sheoran, I. S., Sproule, K. A., Olson, D. J. H., Ross, A. R. S., and Sawhney, V. K. (2006). Proteome profile and functional classification of proteins in Arabidopsis thaliana (Landsberg erecta) mature pollen. Sex. Plant Reprod. 19, 185-196.

Battaglia M and Covarrubias AA (2013) Late Embryogenesis Abundant (LEA) proteins in legumes. Front. Plant Sci. 4:190. doi: 10.3389/fpls.2013.00190
Bies-Ethève N, Gaubier-Comella P, Debures A, Lasserre E, Jobet E, Raynal M, Cooke R, Delseny M (2008) Inventory, evolution and expression profiling diversity of the LEA (late embryogenesis abundant) protein gene family in Arabidopsis thaliana. Plant Mol Biol 67 107-124

Hundertmark, M., and Hincha, D. K. (2008). LEA (late embryogenesis abundant) proteins and their encoding genes in Arabidopsis thaliana. BMC Genom. 9:118.

Garay-Arroyo, A., Colmenero-Flores, J. M., Garciarrubio, A., and Covarrubias, A. A. (2000). Highly hydrophilic proteins in prokaryotes and eukaryotes are common during conditions of water deficit. J. Biol. Chem. 275, 5668-5674.

Pazhamala LT, Purohit S, Saxena RK, et al., (2017) Gene expression atlas of pigeonpea and its application to gain insights into genes associated with pollen fertility implicated in seed formation. J Exp Bot 68:2037-2054.

\section{How to cite this article:}

Antara Das, Kuldeep Kumar, Kishor Tribhuvan, Rekha Joshi, Kumar Durgesh and Kishor Gaikwad 2019. LEA Genes Play Important Role in Seed and Pod Development in Cajanus cajan. Int.J.Curr.Microbiol.App.Sci. 8(10): 716-726.

doi: https://doi.org/10.20546/ijcmas.2019.810.083 